\title{
IMPLEMENTASI FUZZY LOGIC CONTROL PADA SISTEM LAMPU RUMAH DENGAN MENGGUNAKAN MICROCONTROLER ATMEGA8535
}

\author{
Gusrio Tendra \\ AMIK "Tri Dharma" Pekanbaru \\ Jl. Soekarno-Hatta, No.99 B, Labuh Baru, Payung Sekaki, Pekanbaru, Riau \\ e-mail : gusriotendra@amiktridharmapku.ac.id
}

\begin{abstract}
ABSTRAK
Penelitian ini menghasilkan sebuah sistem kontrol lampu rumah otomatis dengan menerapkan logika fuzzy sebagai knowledge yang dapat menetukan kapan waktu lampu harus menyala atau tidak berdasarkan tingkat kecerahan ruangan dan waktu real time. Sistem ini dibangun bertujuan untuk mempermudah manusia dalam hal menghemat listrik. Perangkat keras sistem ini terdiri dari sensor LDR, Microcontroller ATmega8535, Relay, dan Lampu. Cara kerja sistem ini yaitu sensor LDR mendeteksi cahaya dan kemudian data tersebut diolah oleh Microcontroller untuk ditampilkan ke Lampu. Apabila cahaya gelap maka microcontroller menghidupkan lampu, namun jika cahaya terang maka lampu akan mati.
\end{abstract}

Kata Kunci : Logika Fuzzy, Lampu, Microcontroller, Sensor LDR

\begin{abstract}
This research will be designed an automated home lighting system, the system is designed aiming to facilitate human beings in terms of saving electricity. In connection with this problem, this final report describes the design of automated home lighting system by implementing a fuzzy logic algorithm and sensor based LDR microcontroler. The system hardware consists of a sensor LDR, microcontroler ATmega8535, Relay, and Lights. The way this system works is LDR sensor detects light and then the data is processed by microcontroler for display to lights. If the dark light of the microcontroller turn on the lights, but if bright light then the light will die.
\end{abstract}

Keywords : Fuzzy Logic, Lights, Microcontroller, LDR Sensor

\section{PENDAHULUAN}

Suatu penerangan atau lampu diperlukan oleh manusia untuk mengenali objek secara visual. Lampu atau penerangan mempunyai pengaruh terhadap fungsi sebuah ruangan khususnya di rumah.Lampu merupakan suatu penemuan yang sangat penting bagi manusia karena sebelum adanya lampu, kita masih menggunakan lilin sebagai penerangan ketika malam hari. Namun, masa hidup lilin sangat pendek sehingga manusia mulai mencari sumber penerangan baru. Ketika listrik ditemukan, manusia mulai memanfaatkan energi listrik untuk penerangan di malam hari dengan media berupa lampu.
Umumnya pengaturan mematikan dan menghidupkan lampu di rumah digunakan prinsip on-off dimana pada saat ruangan rumah gelap lampu dinyalakan atau dimatikan pada saat rumah atau ruangan terang. Dengan prinsip onoff.

Sistem kontrol adalah proses pengaturan ataupun pengendalian terhadap satu atau beberapa besaran (variabel, parameter) sehingga berada pada suatu harga atau dalam suatu rangkuman harga (range) tertentu (Faroqi, dkk, 2016).

Menjadi suatu masalah dalam pengaturan lampu terutama pada saat kondisi rumah yang bertingkat, dimana harus membutuhkan waktu dan tenaga fisik dalam mematikan dan 
IN F ORM A I I A

Jurnal Informatika, Manajemen dan Komputer, Vol. 13 No. 1 , Mei 2021

eISSN : 2580-3042

pISSN : 1979-0694

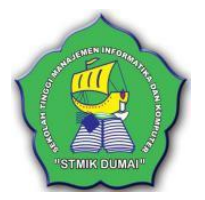

menghidupkan lampu dan juga hanya pada kondisi gelap terang rumah atau ruangan tanpa menghiraukan kontribusi dari luar seperti cahaya matahari. Pada saat kondisi diluar rumah mendung dan lampu dalam rumah atau ruangan menjadi terlalu terang bahkan menyilaukan.

Hal ini sering menyebabkan ketidaknyamanan dari penghuni rumah. Dengan prinsip on-off juga dapat menyebabkan pemakaian energi penerangan yang berlebihan, maka terjadi kurangnya efisiensi dalam penggunaan energy listrik. Oleh karena itu diperlukan pengaturan lampu, untuk dapat menghemat energi listrik. Pengaturan dalam hal ini yakni mematikan dan menghidupkan, terang redup lampu menggunakan prinsip-prinsip pengaturan tegangan masukan, dan pengaturan arus dimungkinkan untuk penghematan energi listrik.

\section{METODOLOGI PENELITIAN}

Pada penelitian ini penulis menggunakan metode pengembangan perangkat lunak untuk mengembangkan Sistem Kontrol Lampu Otomatis ini, adapun metode yang digunakan adalah SDLC Waterfall. SDLC atau Software Development Life Cycle adalah proses mengembangkan atau mengubah suatu sistem perangkat lunak dengan menggunakan modelmodel dan metodologi yang digunakan orang untuk mengembangkan sistem-sistem perangkat lunak sebelumnya, berdasarkan best practice atau cara-cara yang sudah teruji baik (Firmansyah, dan Udi, 2018). Pada penelitian ini penulis menggunakan 4 (empat) tahapan yang dapat dilihat pada gambar 1 berikut :

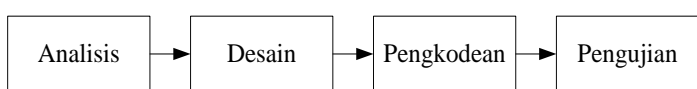

Gambar 1 : Metode Pengembangan Sistem

\section{HASIL DAN PEMBAHASAN}

Pada penelitian ini penulis menggunakan Microcontroller ATMega8535 sebagai perangkat yang digunakan untuk melakukan kontrol terhadap lampu rumah berdasarkan tingkat pencahayaan dan waktu yang diproses menggunakan logika fuzzy.

Logika fuzzy adalah metodologi sistem control pemecahan masalah, yang cocok untuk diimplementasikan pada sistem, mulai dari sistem yang sederhana, sistem kecil, embedded system, jaringan PC, multichannel atau workstation berbasis akuisisi data, dan sistem control (Nasir, dan Suprianto, 2017).

Fuzzy logic control adalah suatu sistem pengendalian yang memanfaatkan logika fuzzy. Logika fuzzy sendiri dipahami sebagai suatu proses pengambilan keputusan berbasis aturan yang bertujuan untuk memecahka nmasalah, dimana system tersebut sulit untuk dimodelkan atau terdapat ambiguitas dan ketidakjelasan (Nugroho, 2017).

Dengan menggunakan komponen Microcontroller sebagai otak pengatur lampu onoff secara otomatis ini akan memudahkan dan mengurangi beban manusia dalam penerangan ruangan. Microcontroller adalah IC yang dapat diprogramberulang kali, baik ditulis atau dihapus. Microcontroller biasa digunakan untuk pengontrolanotomatis dan manual pada perangkat elektronika (Armansyah, 2018).

\section{a. Context Diagram}

Context Diagram (CD) memperlihatkan sistem yang dirancang secara keseluruhan, semua external entity harus digambarkan sedemikian rupa, sehingga terlihat data yang mengalir pada input-proses-output (Afyenni, 2014). Adapun context diagram yang dimaksud dapat dilihat pada gambar 2 berikut :

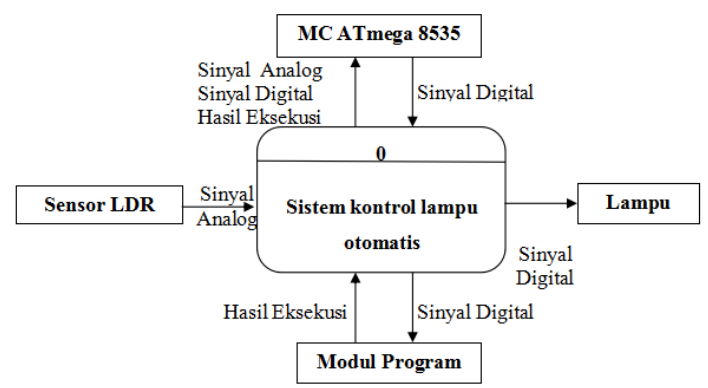

Gambar 2 : Context Diagram

\section{b. Data Flow Diagram (DFD)}

Data Flow Diagram (DFD) adalah suatu model logika data atau proses yang dibuat lebih mendetail dibanding diagram konteks yang diperbolehkan, bisa dicapai dengan mengembangkan diagram. Sisa diagram asli dikembangkan ke dalam gambaran yang lebih terperinci yang melibatkan tiga sampai sembilan proses dan menunjukkan penyimpanan data dan aliran data baru pada level yang lebih rendah (Wibowo, 2013). 
I N F ORM A I I A

Jurnal Informatika, Manajemen dan Komputer, Vol. 13 No. 1 , Mei 2021

eISSN : 2580-3042

pISSN : 1979-0694

Data flow diagram untuk sistem kontrol lampu otomatis dapat dilihat pada gambar 3 berikut:

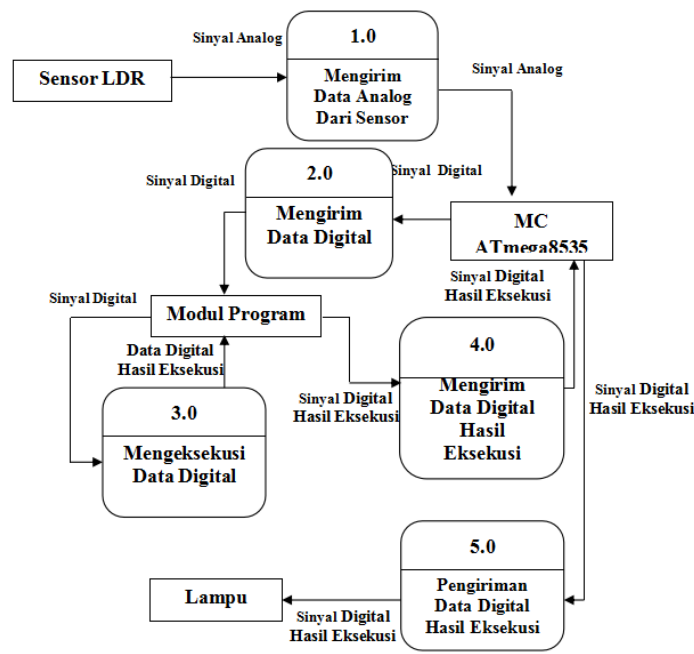

Gambar 3 : Data Flow Diagram

\section{c. Rancangan Fisik}

Adapun rancangan fisik sistem kontrol lampu otomatis adalah sebagai berikut:

1. Sismin ATmega 8535 adalah sebuah chip yang berfungsi sebagai pengontrol rangkaian elektronik dan umunya dapat menyimpan program didalamnya.

2. Power Supply merupakan suatu perangkat elektronik yang berfungsi untuk memberikan tegangan keperangkat lain yang membutuhkannya.

3. Sensor LDR merupakan komponen elektronik yang berfungsi untuk mendeteksi cahaya.

4. Lampu adalah alat yang berfungsi sebagai output untuk memancarkan cahaya.

\section{d. Prinsip kerja alat;}

Sensor LDR mendeteksi cahaya pada lingkungan. Apabila keadaan ruangan gelap maka lampu akan aktif. Gambar rancangan sistem yang dibangun dapat dilihat pada gambar 4 berikut:

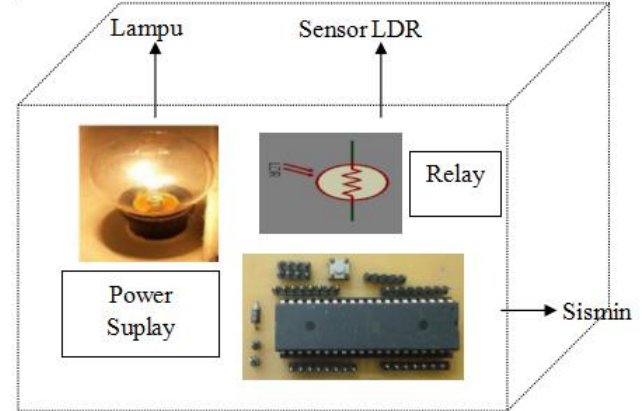

Gambar 4: Rancangan Sistem Lampu Rumah

\section{e. Rancangan Fuzzy Logic}

Nilai keanggotaan atau derajat keanggotaan atau membership function menjadi ciri utama dari penalaran dengan fuzzy logic tersebut (Wibowo, dan Aryanto, 2015). Nilai himpunan logika fuzzy pada sistem kontrol lampu otomatis yang dibangun dapat dilihat pada tabel 1 berikut :

Tabel 1 : Nilai Himpunan Logika Fuzzy

\begin{tabular}{|c|c|c|c|c|c|}
\hline & $\begin{array}{c}\text { Nama } \\
\text { Variabel }\end{array}$ & $\begin{array}{c}\text { Linguistik } \\
\text { Value }\end{array}$ & Range & Domain & Semesta \\
\hline \multirow{6}{*}{ Input } & \multirow{3}{*}{ Cahaya } & Terang & $(0-1)$ & $(-1 ; 0 ; 1)$ & \multirow{3}{*}{$(0-5)$} \\
\hline & & Redup & $(1-2)$ & $(1 ; 1,5 ; 2)$ & \\
\hline & & Gelap & $(2-5)$ & $(2 ; 3,5 ; 5)$ & \\
\hline & \multirow{3}{*}{ Waktu } & Pagi & $(0-12)$ & $(-12 ; 0 ; 12)$ & \multirow{3}{*}{$(0-24)$} \\
\hline & & Siang & $(10-18)$ & $(10 ; 14 ; 18)$ & \\
\hline & & Malam & $(16-24)$ & $(16 ; 20 ; 24)$ & \\
\hline \multirow{3}{*}{ Output } & \multirow{3}{*}{$\begin{array}{l}\text { Keadaan } \\
\text { Ruangan }\end{array}$} & Terang & $(0-3)$ & $(-3 ; 0 ; 3)$ & \multirow{3}{*}{$(0-5)$} \\
\hline & & Redup & $(3-6)$ & $(3 ; 4,5 ; 6)$ & \\
\hline & & Gelap & $(6-10)$ & $(6 ; 8 ; 10)$ & \\
\hline
\end{tabular}

Berdasarkan nilai himpunan pada tabel 1 maka didapatlah rule berikut :

1. If cahaya is Terang and waktu is Pagi then keadaan ruangan is Terang

2. If cahaya is Terang and waktu is Siang then keadaan ruangan is Terang

3. If cahaya is Terang and waktu is Malam then keadaan ruangan is Terang

4. If cahaya is Redup and waktu is pagi then keadaan ruangan is Redup

5. If cahaya is Redup and waktu is Siang then keadaan ruangan is Redup

6. If cahaya is Redup and waktu is Malam then keadaan ruangan is Gelap

7. If cahaya is Gelap and waktu is pagi then keadaan ruangan is Gelap

8. If cahaya is Gelap and waktu is siang then keadaan ruangan is Gelap

9. If cahaya is Gelap and waktu is Malam then keadaan ruangan is Gelap.

Terdapat 2 (dua) buah inputan yang digunakan dalam proses fuzzy yaitu cahaya dan waktu, berikut fungsi keanggotaan untuk masingmasing inputan fuzzy:

Cahaya :

m terang $0 ; \mathrm{x} \leq-1$ atau $\mathrm{x} \geq 1$

$$
\begin{array}{ll}
\mathrm{x}-(-1) /(0-(-1))=(\mathrm{x}+1) / 1 & ;-1 \leq \mathrm{x} \leq 1 \\
(1-\mathrm{x}) /(1-0)=(1-\mathrm{x}) / 1 \quad & ; 0 \leq \mathrm{x} \leq 1
\end{array}
$$

$\mathrm{m}$ redup $0 ; \mathrm{x} \leq 1$ atau $\mathrm{x} \geq 2$

$$
\begin{aligned}
& (\mathrm{x}-1) /(1,5-1)=(\mathrm{x}-1) / 0,5 ; 1 \leq \mathrm{x} \leq 1,5 \\
& (2-\mathrm{x}) /(2-1,5)=(2-\mathrm{x}) / 0,5 ; 1,5 \leq \mathrm{x} \leq 2
\end{aligned}
$$

m gelap $0 ; x \leq 2$ atau $x \geq 5$ 
I N F ORM A I I A

Jurnal Informatika, Manajemen dan Komputer, Vol. 13 No. 1 , Mei 2021

eISSN : 2580-3042

pISSN : 1979-0694

$$
\begin{aligned}
& (\mathrm{x}-2) /(3,5-5)=(\mathrm{x}-2) / 1,5 ; 2 \leq \mathrm{x} \leq 1,5 \\
& (5-\mathrm{x}) /(5-3,5)=(5-\mathrm{x}) / 1,5 ; 3,5 \leq \mathrm{x} \leq 5
\end{aligned}
$$

Waktu :

m pagi $0 ; \mathrm{x} \leq 0$ atau $\mathrm{x} \geq 12$

$$
\begin{aligned}
& (\mathrm{x}-0) /(0-12)=(\mathrm{x}-12) / 12 ;-12 \leq \mathrm{x} \leq 0 \\
& (12-\mathrm{x}) /(12-0)=(12-\mathrm{x}) / 12 ; 0 \leq \mathrm{x} \leq 12
\end{aligned}
$$

$\mathrm{m}$ siang $0 ; \mathrm{x} \leq 10$ atau $\mathrm{x} \geq 18$

$$
\begin{aligned}
& (\mathrm{x}-10) /(14-10)=(\mathrm{x}-14) / 4 ; 10 \leq \mathrm{x} \leq 14 \\
& (18-\mathrm{x}) /(18-14)=(18-\mathrm{x}) / 4 ; 14 \leq \mathrm{x} \leq 18
\end{aligned}
$$

m malam $0 ; x \leq 16$ atau $x \geq 24$

$$
\begin{aligned}
& (\mathrm{x}-16) /(20-16))=(\mathrm{x}-16) / 4 ; 16 \leq \mathrm{x} \leq 20 \\
& (24-\mathrm{x}) /(24-20)=(24-\mathrm{x}) / 4 ; 20 \leq \mathrm{x} \leq 24
\end{aligned}
$$

Untuk output yang diharapkan dari logika fuzzy terdiri dari 1 (satu) buah yaitu keadaan ruangan yang digunakan untuk masukan dalam menonaktifkan dan mengaktifkan lampu secara otomatis. Berikut fungsi keanggotaan untuk masing-masing ouput logika fuzzy :

Keadaan ruangan :

M terang $0 ; X \leq-3$ atau $X \geq 3$

$$
\begin{aligned}
& X-(-3) /(0-(-3))=(X+3) / 3 ;-3 \leq X \leq 0 \\
& (3-X) /(3-0)=(3-X) / 3 \quad ; 0 \leq X \leq 3
\end{aligned}
$$

M redup $0 ; \mathrm{X} \leq 3$ atau $\mathrm{X} \geq 6$

$$
\begin{aligned}
& (\mathrm{X}-3) /(4,5-3)=(\mathrm{X}-3) / 1,5 ; 3 \leq \mathrm{X} \leq 4,5 \\
& (6-\mathrm{X}) /(6-4,5)=(6-\mathrm{X}) / 1,5 ; 4,5 \leq \mathrm{X} \leq 6
\end{aligned}
$$

M gelap $0 ; \mathrm{X} \leq 6$ atau $\mathrm{X} \geq 10$

$$
\begin{aligned}
& (\mathrm{X}-6) /(8-6)=(\mathrm{X}-6) / 2 ; 6 \leq \mathrm{X} \leq 8 \\
& (8-\mathrm{X}) /(10-8)=(8-\mathrm{X}) / 2 ; 8 \leq \mathrm{X} \leq 10
\end{aligned}
$$

Berdasarkan data masing-masing fungsi keanggotaan untuk input dan output dari sistem fuzzy maka dilakukan proses perhitungan dengan menggunakan tools fuzzy Matlab.

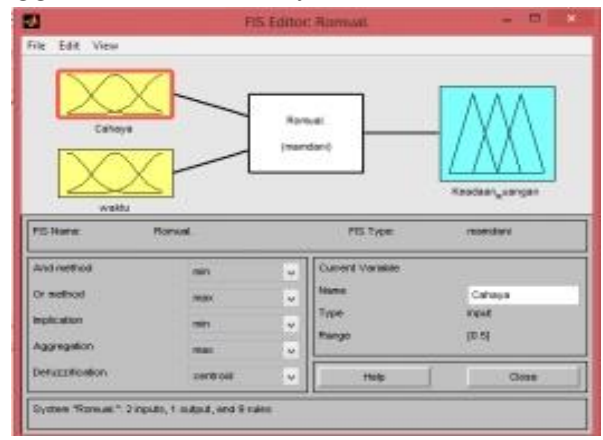

Gambar 5 : Input dan Output Logika Fuzzy

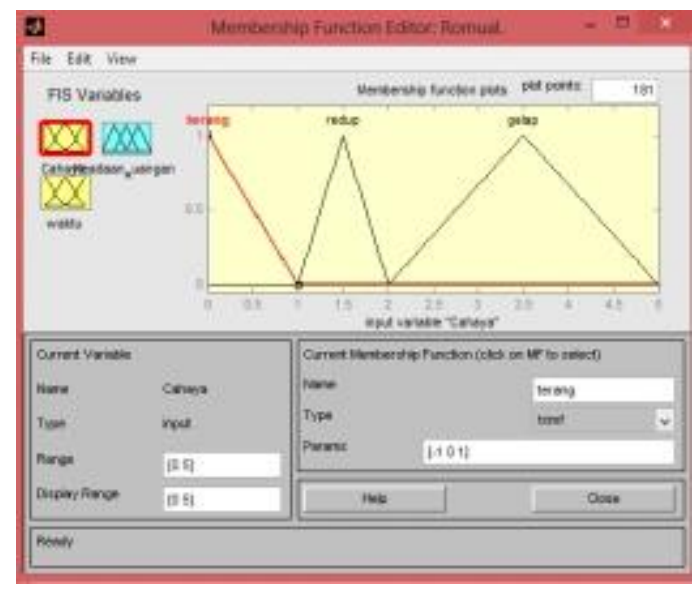

Gambar 6 : Membership Function Input Cahaya

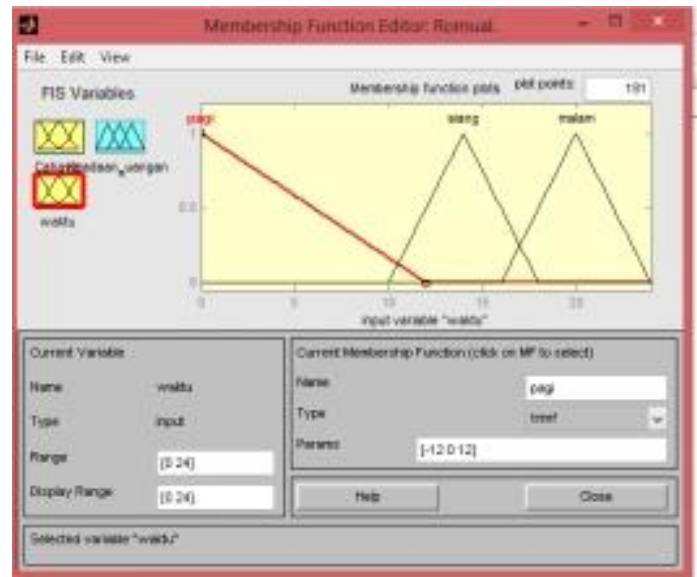

Gambar 7 : Membership Function Input Waktu

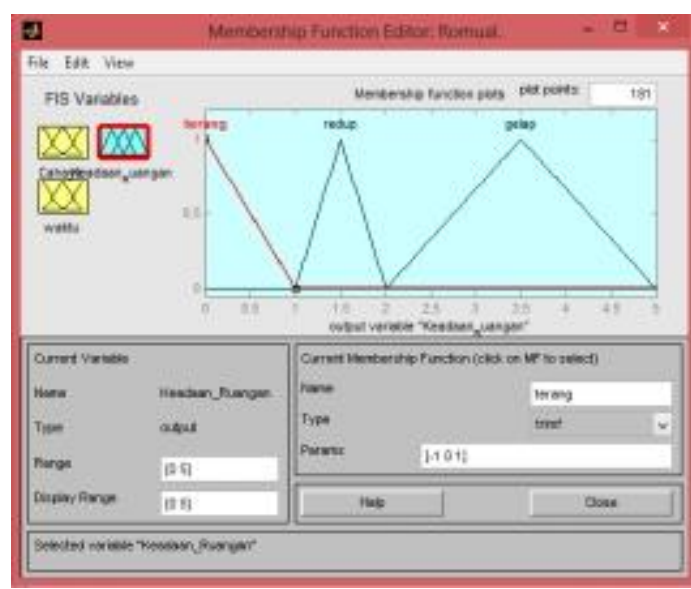

Gambar 8 : Membership Function Ouput Keadaan Ruangan 
INFORM T IKA

Jurnal Informatika, Manajemen dan Komputer, Vol. 13 No. 1 , Mei 2021

eISSN : 2580-3042

pISSN : 1979-0694

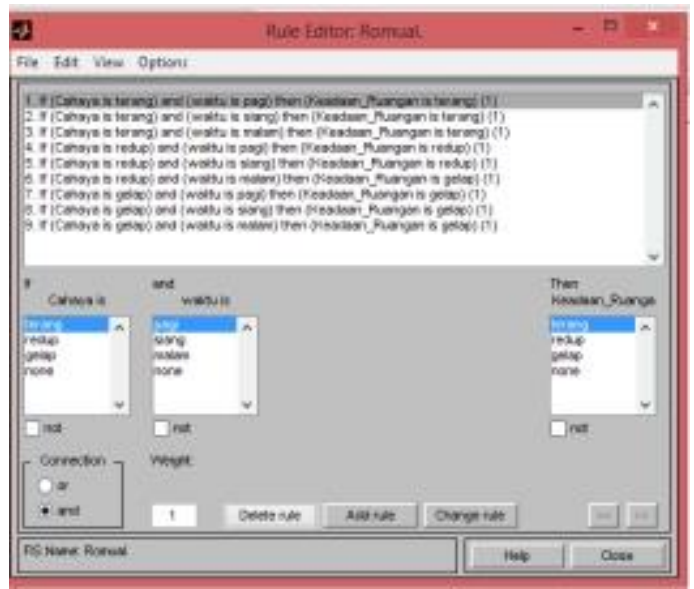

Gambar 9 : Rule Pada Logika Logic

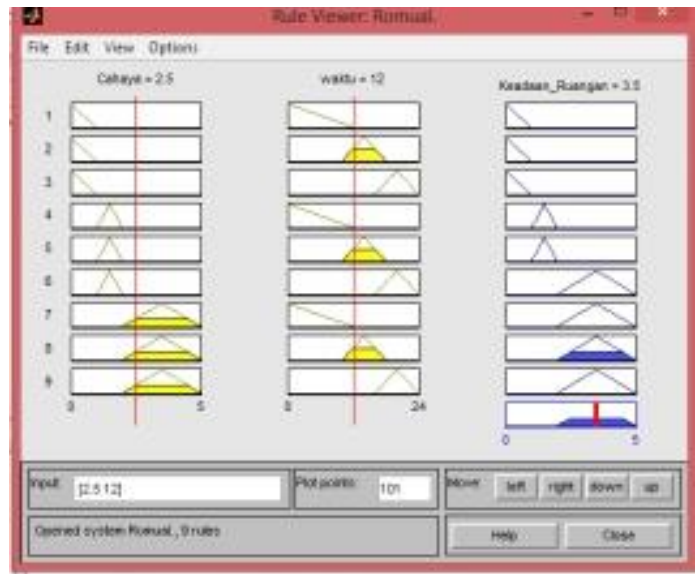

Gambar 10 : Hasil Perhitungan Nilai Logika

$$
\text { Fuzzy }
$$

\section{f. Pengujian Sistem}

Pengujian lampu otomatis dari aplikasi ATmega 8535 dapat dilakukan dengan langkahlangkah berikut:

1. Pertama pasang power supply untuk menghidupkan lampu otomatis. Prosesnya dapat dilihat pada gambar 11 berikut :

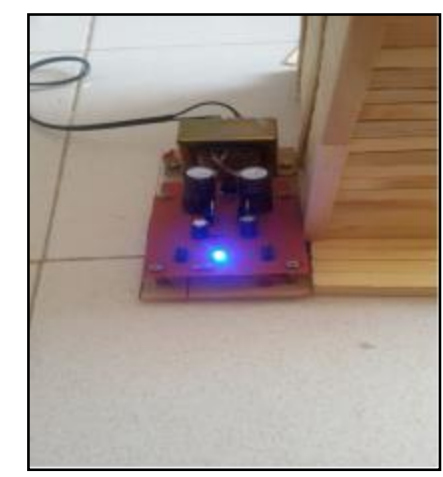

Gambar 11 : Pemasangan Power Supply
2. Setelah itu check kondisi kabel telah terpasang dengan sempurna agar proses dapat berjalan dengan baik. Contoh dapat dilihat pada Gambar 12 berikut :

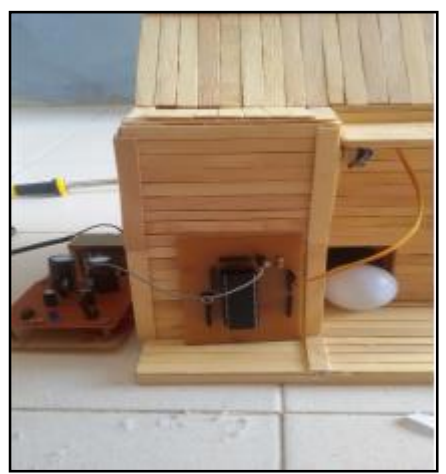

Gambar 12 : Pemeriksaan Kondisi Kabel

3. Pemasangan kabel dari ATMega ke sensor LDR agar sensor berjalan dengan baik pada pengkoneksian dapat dilihat pada gambar 13 berikut :

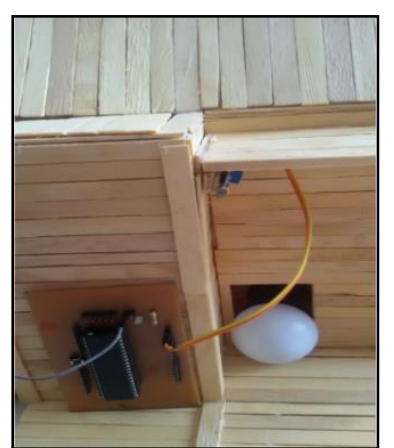

Gambar 13 : Pemasangan Kabel dari ATMega ke Sensor LDR

4. Setelah kompenen dan pengkabelan pada masing-masing rangkaian telah terhubung dengan baik, cara selanjutnya yang akan dilakukan adalah pengujian sistem lampu otomatis. Diman dapat dilihat pada Gambar 14 berikut :

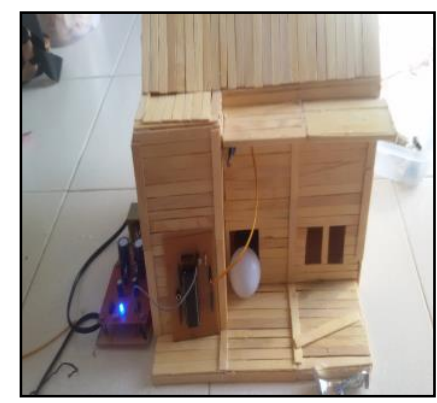

Gambar 14 : Persiapan Pengujian Sistem Lampu Otomatis 
IN F ORM A I K A

Jurnal Informatika, Manajemen dan Komputer, Vol. 13 No. 1 , Mei 2021

eISSN : 2580-3042

pISSN : 1979-0694

5. Hasil pengujian lampu otomatis, dimana dapat dilihat pada Gambar 15 berikut :

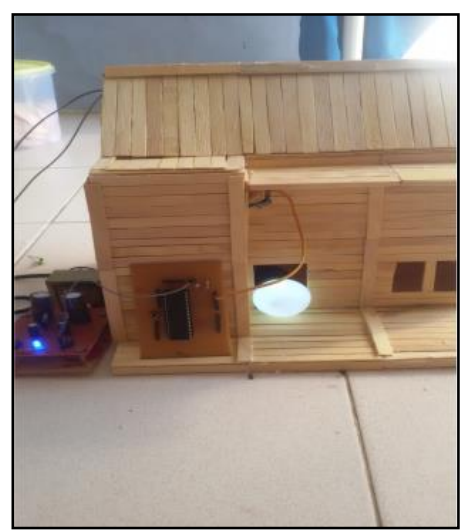

Gambar 15 : Hasil Pengujian Sistem Lampu Otomatis

\section{KESIMPULAN}

Berdasarkan hasil pengujian sistem yang telah dilakukan, maka dapat disimpulkan bahwa sistem kontrol lampu otomatis yang telah dibangun dapat berkerja dengan baik. Penerapan Algoritma Fuzzy Logic dapat digunakan sebagai pengetahuan yang bertujuan untuk membaca kondisi ruangan dan waktu secara real time sehingga waktu menyala dan padam lampu ruangan pada rumah sesuai dengan yang diharapkan dimana tujuan dari sistem ini ialah untuk melakukan penghematan listrik.

\section{REFERENS}

Afyenni, R. (2014). Perancangan Data Flow Diagram untuk Sistem Informasi Sekolah

(Studi Kasus Pada SMA Pembangunan Laboratorium UNP). Teknoif, 2(1), 35-39.

Armansyah. (2018). Bascom-avr dan komponen atmega8535 diimplementasikan pada perangkat penangkap ikan. Jurnal Ilmu Komputer Dan Informatika, 2(April), 7-13.

Faroqi, A., WS, M. S., \& Nugraha, R. (2016). Perancangan Sistem Kontrol Otomatis Lampu Menggunakan Metode Pengenalan Suara Berbasis Arduino. TELKA Telekomunikasi, Elektronika, Komputasi Dan Kontrol, 2(2), 106-117. https://doi.org/10.15575/telka.v2i2.31

Nasir, J., \& Suprianto, J. (2017). Analisis Fuzzy Logic Menentukan Pemilihan Motor Honda dengan Metode Mamdani. Jurnal Edik Informatika, 3(2), 177-187.

Nugroho, E. A. (2017). Sistem Pengendali Lampu Lalulintas Berbasis Logika Fuzzy. Jurnal SIMETRIS, 8(1), 75-84.

Udi, \& Firmansyah, Y. (2018). Penerapan Metode Sdlc Waterfall Dalam Pembuatan Sistem Informasi Akademik. Jurnal Teknologi \& Manajemen Informatika, 4(1), 184-191.

Wibowo, A. T. (2013). Pembuatan Aplikasi ECommerce Pusat Oleh-Oleh Khas Pacitan. Journal of Chemical Information and Modeling, 53(1), 1-5.

Wibowo, F., \& Aryanto, D. (2015). Prototype Model Sistem Pendukung Keputusan Berbasis Fuzzy Logic Metode Mamdani untuk Pemilihan Lulusan Terbaik di Universitas Muhammadiyah Purwokerto ( Prototype of Decision Support System Based Mamdani Method Fuzzy Logic for Best Graduate Selection at Un. JUITA (Jurnal Informatika) UMP, III, 121-127. 